\title{
The Application of Psychometric Tests in Human Resource Management
}

\section{R P van der Merwe}

Department of Industrial and Organisational Psychology, University of Port Elizabeth

\section{ABSTRACT}

Psychometric tests are widely used as aids in occupational decisions, including the selection and classification of human resources. Recent and ongoing developments in South African labour legislation, especially the implications of the Employment Equity Act, highlight once again the importance of validating all instruments used for assessment and selection purposes. This is a follow-up study, reporting on an investigation into psychometric testing in industry today. Information was gathered to establish which psychometric tests are presently used, and for what purpose. Biographical information on each company concerned is supplied, including the number of employees. The role of psychometric tests in the selection procedure is discussed, as well as the levels at which the tests were applied. The various tests used, as well as the users, are indicated, and comments, recommendations and shortcomings discussed.

JEL J29

\section{INTRODUCTION}

One of the critical elements in the pursuit of outstanding organisational performance, is the selection and development of the best possible staff. Intemational as well as local research has demonstrated the role that psychometric assessment can play in significantly enhancing the selection process for both new entrants and internal promotions. Effective psychometric assessment can alsa play a key role in staff development processes - an important challenge facing South Africa.

Psychometric tests are commonly employed as aids in occupational decisions, including the selection and classification of human resources. From the assembly-line operator or filing clerk to top management, there is scarcely a type of job for which some kind of psychometric test has not proved helpful in 
such matters as hiring, job assignment, transfer, promotion, or termination (Anastasi \& Urbina, 1997).

According to Owen and Taljaard (1996), it appears that psychometric tests can contribute to the efficiency of selection and placement in industry, if carefully and responsibly used. Friedenberg (1995) refers to research which compares different selection procedures (application forms, letters of reference, interviews, testing) and confirms that although each technique has its own merits, standardised tests are psychometrically the soundest.

Moerdyk, in an article by Mittner (1998), reportedly mentions that if psychometric tests are handled with insight and sensitivity, they remain the most effective means of predicting behaviour. Kemp (1999) says that tests are an aid in the selection process, and if properly used, supply invaluable information which is not easily gleaned in interviews. According to Van der Walt (1998), experience has proved that tests are generally more reliable and valid than other available techniques. Studies in trade and industry have indicated that psychometric tests are about four times more effective than screening interviews.

Given the high costs of staff turnover and the heightened importance of identifying key staff from previously disadvantaged population groups, psychometric assessment can make a major contribution to human resource management in South Africa. In the light of the above-mentioned points, it was decided to investigate the application of psychometric tests in human resource management. This study is a follow-up report on the findings of such ongoing exploratory research (Van der Merwe, 1999), undertaken to establish which psychometric tests are used and for what purpose, in industry today.

\section{RECENT LEGISLATION}

To protect the public against abuses, the use of psychometric tests is legally specified (Medical, Dental and Supplementary Health Service Professions Act, 1974). Specialised training is required to determine which tests will give the best results in particular circumstances, and to interpret the results responsibly. Tests may only be used by registered psychologists, or other suitably qualified and registered persons under the supervision of psychologists.

Recent and ongoing developments in South African labour legislation, also emphasise the need for the responsible use of psychometric tests and other psychological assessment procedures. According to Eckstein (1998), the Employment Equity Act highlights the importance of the validation of any 
instrument to be used for assessment and selection purposes. This represents a definite move towards making selection decisions more scientific. Kriek (1998) also welcomes this legislation which, according to him, can only help to improve current assessment practices in South Africa. According to Roodt (1998), one purpose of the Act is to ensure that psychometric tests are used in an unbiased manner, resulting in faimess.

The Employment Equity Act (1998: 8) inter alia determines the following:

"Psychological testing and other similar assessments of an employee are prohibited unless the test or assessment being used-

a) has been scientifically shown to be valid and reliable;

b) can be applied fairly to all employees; and

c) is not biased against any employee or group"

To deal with this in practice, one will first of all need a good and accurate method of job analysis - breaking down the job into dimensions or competencies. Next one would need simple and verifiable tests for these job-related competencies such as work sample tests or assessment centres. One would of course also have to keep statistics of applicants at all stages of the selection process, so as to defend oneself against any allegations of differential impact.

\section{THE SELECTION PROCESS}

There is no fixed, generally accepted, standard selection procedure that is at present used by everybody. A selection procedure may be fairly simple or very complex, depending on the nature of the organisation, the task for which individuals are being selected, and the philosophy of the human resource management (Aiken, 1994).

The vast majority of employee selection programmes are based on the successivehurdle technique. This means that to be hired, applicants must successfully pass various screening devices. Some candidates are rejected at each step or hurdle. Psychometric tests can be of great value in employee selection because of their objectivity and validity (Schultz \& Schultz, 1998). It must however be regarded as one possible step in the selection process - merely an aid, never to be used on its own, or to replace the whole selection procedure. The general nature of the selection process is set out in Figure 1. 
Figure 1 The selection process

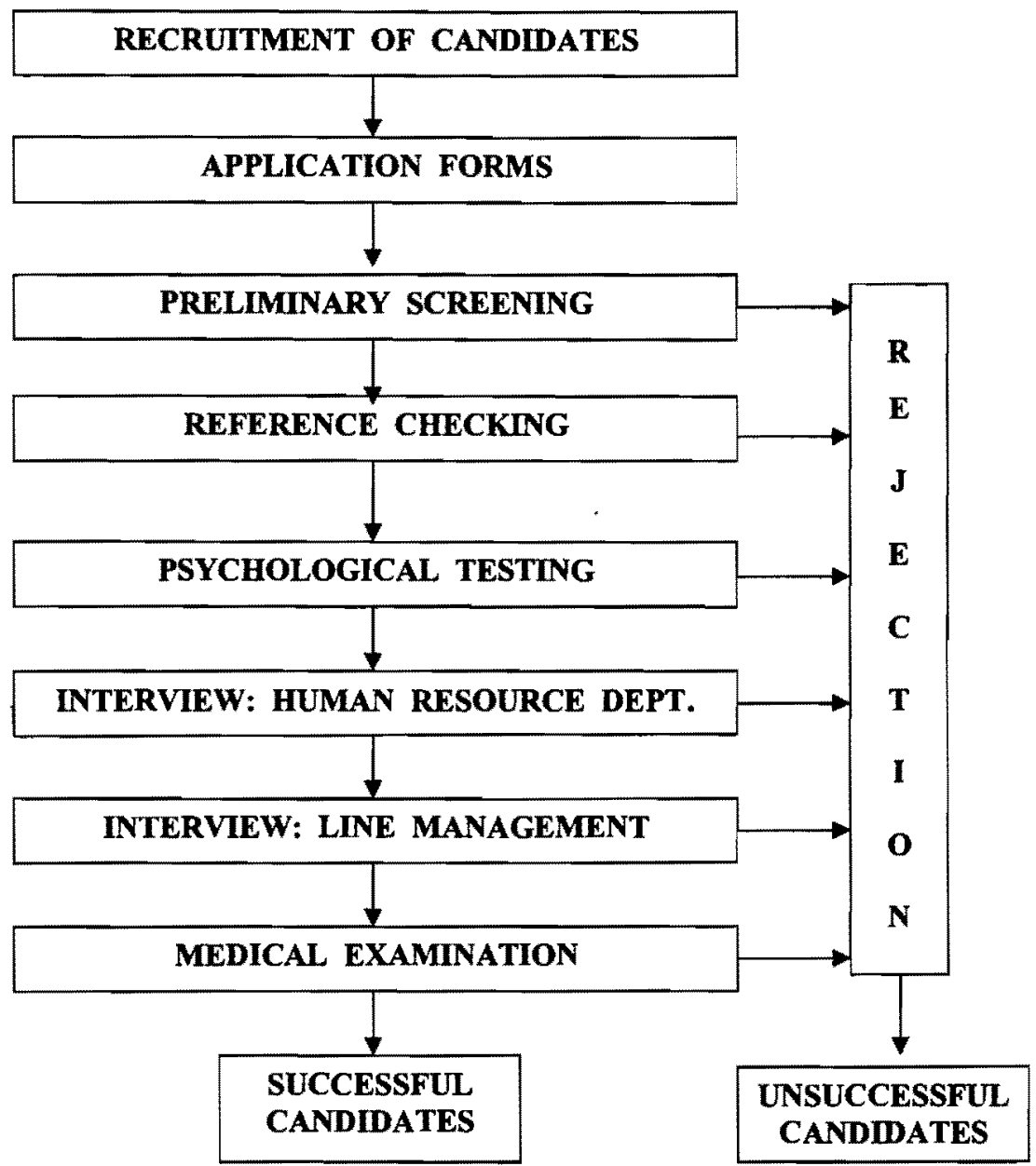

\section{METHOD}

\subsection{Sample}

A non-probability convenience sample of organisations was drawn from the Port Elizabeth and Uitenhage area of the Eastern Cape Province. The research can 
thus be regarded as a qualitative investigation. Background information about the various organisations selected is supplied in Table 1.

\section{Table 1 Participating organisations}

\begin{tabular}{|c|c|c|}
\hline $\begin{array}{c}\text { Organi } \\
\text {-sation }\end{array}$ & Type of business & Employees \\
\hline $\bar{A}$ & $\begin{array}{l}\text { Branch of large insurance company (nationwide } \pm 13000 \\
\text { employees) }\end{array}$ & 600 \\
\hline B & $\begin{array}{l}\text { Branch of large banking group (nationwide } \pm 37000 \\
\text { employees) }\end{array}$ & 1300 \\
\hline $\mathrm{C}$ & $\begin{array}{l}\text { Government department responsible for security, law and } \\
\text { order }\end{array}$ & 19000 \\
\hline$\overline{\mathrm{D}}$ & $\begin{array}{l}\text { Branch of large beverage company (nationwide } \pm 8000 \\
\text { employees) }\end{array}$ & 1000 \\
\hline E & Motor manufacturing company & 6500 \\
\hline F & $\begin{array}{l}\text { Kegional office of telecommunications company (nation- } \\
\text { wide } \pm 57000 \text { employees) }\end{array}$ & 4500 \\
\hline $\mathbf{G}$ & Motor manufacturing company & 4000 \\
\hline $\mathbf{H}$ & $\begin{array}{l}\text { Technical and network services business unit of } \\
\text { telecommunications company (nationwide } \pm 57000 \\
\text { employees) }\end{array}$ & 2000 \\
\hline$I$ & Tyre manufacturing company & 2000 \\
\hline
\end{tabular}

From Table 1 it appears that the participating organisations cover a wide range of different kinds of economic activities.

\subsection{Procedure}

Postgraduate students in Industrial and Organisational Psychology acted as field workers in this study. They were thoroughly briefed by the researcher on the interviewing procedure used. The data were collected by means of individual interviews that these students conducted with a designated representative from the human resource department of each organisation involved.

Mostly these representatives were personally responsible for the testing in their organisations. Where this was not the case, the representative was the person locally involved with the testing arrangements and administration in an organisation. These people provided the information that was used in this research, by discussing the testing policy of their organisation with the interviewers. 


\section{Data Analysis}

All the data gathered by means of these interviews, were analysed by means of content analysis. Inferences were made on inspection of the data collected.

\section{RESULTS}

The results of this research are presented in the following format:

Brief testing policy of the organisation

Tests used in the organisation

Test users (administrators) in the organisation

Comments by organisational representatives

Based on the questions asked during the interviews, the following information on each organisation, was made available.

\subsection{Brief testing policy}

The role of psychometric testing in the selection procedure, as well as the levels at which tests are applied in each participating organisation, is discussed next.

\section{ORGANISATION A}

Organisation A makes use of a clearly defined selection procedure which includes the following: application blanks, preliminary interviews, psychometric tests, final selection interviews and reference checking. Psychometric tests are merely used as an additional aid in the selection process and are required to be culture-fair and non-discriminatory. Employment equity enjoys a high priority in this organisation.

In addition, tests are used for selection and management information, more so at the lower levels of employment. At management level, assessment centres are used for selection and promotion purposes.

\section{ORGANISATION B}

This organisation uses a clearly stated and defined selection procedure, in different steps. These were recently revised to comply with the latest labour legislation. The attitude is that it is not always equally important to use psychometric tests in the selection process. The specific job under consideration 
will indicate whether it is necessary to do testing or not. Tests are never used on their own - always together with an interview and other input.

Tests are used at all levels in this organisation for selection, placement, promotion and strategic restructuring. In this case, assessment centres are not used because they are regarded as too expensive and time consuming.

\section{ORGANISATION C}

Organisation $\mathrm{C}$ makes use of a clearly stated selection procedure which includes: application forms, reference checking, testing and diagnostic interviewing. Tests are never chosen at random - a thorough job analysis is first conducted to determine the skills that are needed to perform the job successfully.

Tests are used at all levels in this organisation: for selection, placement, training and transfers, but not for promotions. Although use was previously made of assessment centres, this is no longer so.

\section{ORGANISATION D}

This organisation uses a clearly stated selection procedure and policy, in which it makes use of application blanks, preliminary interviews, psychometric tests, diagnostic interviews and reference checking.

Psychometric tests are regarded as important in this organisation's selection process. The purpose of psychometric tests is to provide specialist information in support of managerial decision-making, by improving the accuracy of decisions regarding the selection, promotion and development of employees. The assessments should also assist individual employees in gaining insight into themseives, for the purpose of their self-development.

Tests are used in this organisation for all positions from shopfloor level to higher positions. They are however also used for certain positions where specific psychometric and psychological make-up is deemed necessary (e.g. apprentices and bursars).

\section{ORGANISATION E}

This organisation makes use of a selection procedure, which inter alia includes interviews. All information gathered during the selection process is used by the organisation in making final appointment decisions. Tests are mainly used for 
selection purposes, mostly at managerial level, though a few also at entry grade levels.

\section{ORGANISATION F}

Organisation $\mathrm{F}$ makes use of a clearly stated selection procedure, which includes curriculum vitaes, psychometric testing, assessment centres, interviews and reference checking. The approach is not to use tests in isolation, but rather as a means of verifying the information obtained from other selection devices. Tests are used to facilitate selection, placement and promotion decisions, also for development and training purposes. Tests are administered at all levels, from auxillary, lower-level to management positions.

\section{ORGANISATION G}

This organisation makes use of a structured selection procedure. The main instruments used are the interview, application blanks, psychometric testing, reference checking and sometimes assessment centres. It is however moving away from the use of assessment centres. The main reasons for this are that it is very expensive, extremely time consuming and that there has to be fairly intensive training of the adjudicators involved. The organisation employs psychometric tests for selection, placement, promotions, as well as to establish training needs. Tests are used at the lower levels of the organisation, as well as when selecting candidates for supervisory positions or management level.

\section{ORGANISATION H}

In this organisation a very strict selection procedure is followed. Psychometric tests are used in conjunction with the interview as well as application blanks. The results of the tests are evaluated along with the outcomes of the other procedures used. Tests are mainly used for selection purposes. When dealing with higher level positions, case studies and simulations are occasionally also applied.

\section{ORGANISATION I}

Oganisation I has a clearly stated selection process in which use is made of application blanks, reference checking, interviews, assessment centres and psychometric testing. Psychometric testing is also used for promotion purposes, to determine training needs, and for counselling. It is however regarded as an additional tool to try to inject some objectivity into what might otherwise be a very subjective process. It is extensively used at worker entrance level, as well as for recruitment at management level. 


\subsection{Tests used}

In Table 2 the various tests used by the various organisations are indicated. Some tests are used by two or more organisations, and the most widely applied test is the $16 \mathrm{PF}$, which is used by seven organisations. Note that in most cases, a specific test is used by one organisation only. For the sake of clarity, a brief description of the abbreviations used for the various tests is given after Table 2.

Table 2 Tests used by the various organisations

\begin{tabular}{|l|c|c|c|c|c|c|c|c|c|}
\hline $\begin{array}{l}\text { ORGANI- } \\
\text { SATION: }\end{array}$ & $\mathrm{A}$ & $\mathrm{B}$ & $\mathrm{C}$ & $\mathrm{D}$ & $\mathrm{E}$ & $\mathrm{F}$ & $\mathrm{G}$ & $\mathrm{H}$ & $\mathrm{I}$ \\
\hline TESTS: & & & & & & & & & \\
\hline 16 PF & $\mathrm{X}$ & $\mathrm{X}$ & $\mathrm{X}$ & & $\mathrm{X}$ & $\mathrm{X}$ & $\mathrm{X}$ & & $\mathrm{X}$ \\
\hline SORT & & $\mathrm{X}$ & $\mathrm{X}$ & & & & & & \\
\hline TAT & & $\mathrm{X}$ & & & & & & & \\
\hline MBTI & $\mathrm{X}$ & & & & & $\mathrm{X}$ & $\mathrm{X}$ & & \\
\hline MMPI & & & & $\mathrm{X}$ & & & & & \\
\hline 19 FII & $\mathrm{X}$ & & & & & & & & \\
\hline HL Bat & $\mathrm{X}$ & $\mathrm{X}$ & & & & & & & \\
\hline INT Bat & $\mathrm{X}$ & $\mathrm{X}$ & $\mathrm{X}$ & & & & & & \\
\hline NORM Bat & & $\mathrm{X}$ & & & & & & & \\
\hline SAT & $\mathrm{X}$ & & $\mathrm{X}$ & & & $\mathrm{X}$ & $\mathrm{X}$ & & \\
\hline AAT & & & $\mathrm{X}$ & & & & & & \\
\hline PAB & $\mathrm{X}$ & & & & & & & & \\
\hline SAWAIS & & & $\mathrm{X}$ & $\mathrm{X}$ & & $\mathrm{X}$ & & & \\
\hline CPA & & & & $\mathrm{X}$ & & & & & \\
\hline DOVER & & & & & $\mathrm{X}$ & & & & $\mathrm{X}$ \\
\hline GI EXeTc & & & & & $\mathrm{X}$ & & & & \\
\hline $\begin{array}{l}\text { PRESENTA- } \\
\text { TION }\end{array}$ & & & & & $\mathrm{X}$ & & & & \\
\hline IN-BASKET & & & & & $\mathrm{X}$ & & & & \\
\hline HL FCT & & & & & & $\mathrm{X}$ & $\mathrm{X}$ & $\mathrm{X}$ & \\
\hline SDS & & & & & & $\mathrm{X}$ & & & \\
\hline OPQ/CCSQ & & & & & & $\mathrm{X}$ & & $\mathrm{X}$ & \\
\hline PTB & & & & & & $\mathrm{X}$ & & & \\
\hline TTB & & & & & & $\mathrm{X}$ & & $\mathrm{X}$ & \\
\hline PPA & & & & & & & & & $\mathrm{X}$ \\
\hline
\end{tabular}

Sixteen Personality Factor Questionnaire (16 PF): This measures 16 primary personality traits and is inter alia used by industry and business in the selection, placement and promotion of employees by predicting important job-related 
criteria such as work efficiency, tolerance of routine etc. (Huysamen, 1996; Spangenberg, 1990).

Structured-Objective Rorschach Test (SORT): The SORT is based on the traditional Rorschach Test, and its aim is to obtain psychologically meaningful data by means of which a broad overall picture of the individual can be obtained (Spangenberg, 1990). Together with data from other tests, this can then be used for counselling, selection and the prediction of job success.

Thematic Apperception Test (TAT): This is a projective personality test which is regarded as especially suited to assessing motivation, such as the need for achievement or affiliation (Huysamen, 1996).

Myers-Briggs Type Indicator (MBTI): This test was designed to implement Jung's theory of type, as understood by the author (Isabel Myers). More specifically, the aim is to identify the basic preferences of people with regard to perception and judgement. These preferences are: Extraversion-Introversion, Sensing-Intuition, Thinking-Feeling, and Judgement-Perception (Spangenberg, 1990).

Minnesota Multiphasic Personality Inventory (MMPI): This is a broad-band test designed to assess a number of the major patterns of personality and emotional disorders. To a certain extent it highlights signs of pathology in the people tested (Aiken, 1994; Anastasi \& Urbina, 1997).

Nineteen Field Interest Inventory (19 FII): This inventory measures occupational interests with respect to 19 broad fields of activity. It also measures the extent to which a person is actively or passively interested in the 19 fields, as well as the extent to which the interests are work- or hobby-related (Owen \& Taljaard, 1996).

High Level Battery (HL Bat): This battery provides a measure of general intelligence, arithmetical ability and certain language abilities. It can be used for vocational guidance as well as the selection and classification of high level employees, and is suitable for testees with matric or higher qualifications (Huysamen, 1996; Owen \& Taljaard, 1996; Spangenberg, 1990).

Intermediate Battery (INT Bat): This battery was designed to measure certain mental abilities, including mental alertness, arithmetical ability, some aspects of language, and clerical skills. It can be used in vocational guidance as well as for the selection of persons who have had not more than 12 years of schooling (Huysamen, 1996; Owen \& Taljaard, 1996; Spangenberg, 1990). 
Normal Battery (NORM Bat): This battery was designed to measure a number of mental abilities, including mental alertness, computation and certain language skills. It can be used in vocational guidance as well as in the selection of persons with 9 to 10 years of schooling (Huysamen, 1996; Owen \& Taljaard, 1996; Spangenberg, 1990).

Senior Aptitude Tests (SAT): This test was designed to measure a number of aptitudes and the results can be used for vocational guidance and selection purposes (Huysamen, 1996; Owen \& Taljaard, 1996).

Academic Aptitude Test (AAT): The aim of this test is to serve as an aid in the guidance of senior pupils with regard to subject and career choice. More specifically, it provides an assessment of general intellectual, verbal, mathematical and spatial ability. It may also be of value in selection and placement decisions (Spangenberg, 1990).

Programmer Aptitude Battery (PAB): This battery measures aptitude for computer programming. It is intended to be used on individuals who have little or no experience in computer programming, although it might also be useful in selecting existing programmers. It should not be used on persons who have not passed matric (Owen \& Taljaard, 1996).

South African Wechsler Adult Intelligence Scale (SAWAIS): This scale is a verbally administered individual test designed to evaluate the intellectual functioning of the older child and adult (Huysamen, 1996; Spangenberg, 1990).

Career Path Appreciation (CPA): This is based on a stratified systems theory and assesses a manager's ability to deal with challenges of varying complexity. Judgement in making decisions under a variety of conditions of uncertainty is assessed, along with ability in long-term and short-term thinking. This form of evaluation works on a semi-structured interview system.

Dover/Vienna Test System (DOVER): This is a machine with lights of different colours, and the testee is expected to coordinate the hand switches with the different lights of the machine as they come on and go off. The performance of the candidate is scored automatically. Performance under stress, orientation ability, levels of productivity, and learning ability, are some of the aspects evaluated by this system.

Group Interaction Exercise (GI Exerc): This can be regarded as a group problem solving exercise. The group of candidates is given a problem to discuss and within fifteen minutes they must arrive at a solution. Afterwards, the 
contribution of each group member is evaluated, and it is considered whether it contributed to the final outcome reached by the group as a whole.

Presentation: This exercise is similar to the previous (group interaction exercise) one, except that the candidate works as an individual. The candidate is given a problem and allowed five minutes to think about a way of solving it. Then the candidate has to make an oral presentation, arguing and demonstrating how the problem can best be solved.

In-basket Exercise: This exercise consists of samples of typical items or activities found in the department in which a vacancy exists. Candidates are asked to indicate what action should be taken with regard to each item or activity. In other words, it is a type of simulation exercise in which the person must deal with a pile of paperwork - letters, reports, phone messages, and so on - typical of what might be found in a manager's in-basket.

High Level Figure Classification Test (HL FCT): This is a non-verbal pencil and paper test, which assesses abstract reasoning ability. It is intended for use in selecting staff for positions that require a moderate to high level of abstract conceptual functioning - more than mere routine activities (Spangenberg, 1990).

Self-Directed Search Questionnaire (SDS): The rationale of this questionnaire is to measure interest. The questionnaire fits into the broad context of career planning, since it provides important information about an individual's occupational interests, and supports the link between personal and occupational information (Owen \& Taljaard, 1996).

SHL Occupational Personality Questionnaire (OPQ): This questionnaire is applied to assess a comprehensive range of personality characteristics, including: relationships with people; thinking and problem solving style; emotions, motivation and drives; team working styles; leadership or subordinate styles; selling and influencing styles (SHL, 1996).

SHL Customer Contact Styles Questionnaire (CCSQ): This questionnaire has been designed to measure sixteen dimensions of personality relevant to nonsupervisory staff working in sales or customer service roles (SHL, 1996).

SHL Personnel Test Battery (PTB): This is a battery consisting of various tests, used to select clerical and administrative staff. Emphasis is on practical skills and the needs of the modem workplace, including equal opportunity issues (SHL, 1996). 
SHL Technical Test Battery (TTB): This is a battery consisting of various tests. It is used in the selection of a wide range of technical staff, including school leavers and candidates with work experience (SHL, 1996).

Thomas Personal Profile Analysis (PPA): This is a questionnaire where the person being evaluated has to select the words which most, and least, apply to $\mathrm{him} /$ her. By charting these choices scientifically, insight is obtained into how this person would behave at work. It can provide helpful understanding of how this person copes with his/her environment and what his/her attitudes are likely to be. It also provides insight into possible performance in a particular function (Thomas International, undated).

\subsection{Test users (Administrators)}

Table 3 shows the persons responsible for testing in the various organisations. Note that they are the test users and not necessarily the same people as those who provided the information about each organisation.

Table 3 Test users in the various organisations

\begin{tabular}{|c|l|}
\hline $\begin{array}{c}\text { Organi- } \\
\text { sation }\end{array}$ & \multicolumn{1}{|c|}{ Test user } \\
\hline A & $\begin{array}{l}\text { Psychometrists or psychologists: Special manager at head office } \\
\text { overall responsible for testing in company and correct procedures and } \\
\text { standards of testing. }\end{array}$ \\
\hline B & Psychometrists or psychologist. \\
\hline C & Psychometrists or psychologists. \\
\hline D & $\begin{array}{l}\text { Use external consulting psychologists: Consulting psychologist } \\
\text { available at head office. }\end{array}$ \\
\hline E & $\begin{array}{l}\text { No qualified test user: Interpretation done by external consulting } \\
\text { psychologists. }\end{array}$ \\
\hline F & Psychometrists or psychologists. \\
\hline G & $\begin{array}{l}\text { Psychometrists: Use is also made of external consulting } \\
\text { psychologists. }\end{array}$ \\
\hline H & Psychometrists or psychologist. \\
\hline I & External psychologist and other consultants \\
\hline
\end{tabular}

From Table 3 it appears that most of the organisations have their own psychometrists or psychologists. The others make use of consulting psychologists. 


\subsection{Comments by organisational representatives}

In organisation $\mathbf{A}$ they are satisfied with the tests they are using in some areas, less so in other areas. Tests are however useful in the identification of the potential of individuals whose schooling background is not up to standard. Presently the organisation is looking at the validity of the tests used, scxhooling and attempting to implement tests more equitable in terms of culture.

According to the feedback from organisation B, a test is only as good as the person who uses it. It is strongly felt that tests must be used in the right way, and that we still have a long way to go to achieve culturally fair tests.

In general, organisation $C$ is satisfied with the tests used there. As long as the tests are used for the purpose for which they were intended, they are seen to be a useful aid. Many of the tests used are however outdated in some respects, and should be updated. Because they question the culture-fairness of the tests used, industrial psychologists at head office have standardised most of the tests for the organisation's workforce, with the result that norms differ for different culture groups. Given the problems relating to culture-faimess, the organisation no longer uses psychometric tests in the promotion of employees (to evaluate leadership potential). It now makes use of a method called Targeted Selection (also known as the assessment interview).

In the case of organisation $\mathbf{D}$ there is a perception that too much emphasis may be placed on test results. To improve the level of interpretation of results, test results and work performance results are frequently correlated at head office. The organisation is very much committed to culture-faimess in their testing, as a result of which the $16 \mathrm{PF}$ was removed from the batteries of tests.

Organisation E seemed generally satisfied with the tests being used there, because these proved to test what they actually purported to test. It however questions the culture-faimess of the $16 \mathrm{PF}$.

Overall, in organisation $\mathbf{F}$ there is satisfaction with the tests being used. It is felt that some of the tests are possibly outdated, especially regarding the norms being used. To an extent the unions are questioning their use of psychometric testing and until tests can undisputedly be shown to be culture-fair, the role of testing is expected to decline in this organisation. There is a feeling that many uncertainties surround the use of tests in the new South Africa. This is one of the reasons why the organisation started using the tests from SHL (which SHL maintains to be culture-fair). 
In organisation $\mathbf{G}$ the general feeling is that the tests used are culture-fair, but the accompanying norm tables are badly outdated. To an extent it also questions the reliability and validity of the tests. The wish is to employ tests that are more culture-fair, and the various selection instruments are at present being reconsidered very carefully.

According to organisation $\mathbf{H}$, the lack of culture-faimess is a major problem in psychometric testing. This organisation feels very strongly about culture-fair tests because of its multicultural work force.

It appears that organisation $I$ is satisfied with the psychometric testing it employs - the actual intention is to use these tests even more in future to establish individual potential. It is however emphasised that testing is only an additional tool to be used, to try and inject some objectivity into what could otherwise be a very subjective process.

\section{DISCUSSION AND RECOMMENDATIONS}

From this study of the application of psychometric tests in human resource management, it appears that psychometric tests are not used just on their own in practice. As an additional aid in decision making, the tests normally form part of a defined procedure which includes certain different, interrelated, and specific steps, as well as other tools. These seem to be used not only for selection purposes, but for placement, promotion, transfers, training and development. Furthermore, it appears that these tests are often used at different levels in the organisations which participated in this study.

The tests used by these organisations (see Table 2), are all mainly South African-specific and -validated material, distributed by the Human Sciences Research Council and a few other organisations. Most test administrators of these organisations (see Table 3) are trained and qualified test users, well aware of the laws and nules that govern psychometric testing in South Africa. To conform to these regulations, some of the organisations even make use of the services of external consulting psychologists. The author therefore concludes that psychometric testing is conducted at a professional level in the organisations surveyed. This is contrary to a recent worldwide investigation of testing and the use of tests (Batram \& Coyne, 1998), which found that almost $60 \%$ of test users were not specifically trained in the use of psychological tests.

From comments by the organisation representatives interviewed in the present study, it appears that they are largely satisfied with the tests being used. Mention was made that some of the tests and test material used were outdated. 
It is also stressed that test users must be well trained and tests must be used for the purpose for which they were designed. Bartram and Coyne (1998) found in their survey that there is a worldwide lack of appropriate training in testing and test use. They also found a perception that test misuse is a worldwide problem, and that the best way to counter it is through training and increased public understanding.

According to Huysamen (1996), one of the major stumbling blocks regarding the use of psychometric tests in South Africa, stems from the complexity of designing tests that may be used across a diversity of language and cultural backgrounds. Of major concern are the implications of possible discrimination, and therefore many organisations are presently working towards the validation of tests in their own work environments. The definite need for culture-fair tests was frequently expressed by the representatives of the organisations that participated in this investigation. It thus appears that their intention is to implement fair and equal treatment to all individuals.

In this regard it is interesting to note that the $16 \mathrm{PF}$ is the one test used by most of these organisations, all except two (organisations D and H). Organisation D recently removed it from their batteries of tests because it was found not to be culture-fair. Another organisation (organisation E) still using it, also questions the culture-faimess of the $16 \mathrm{PF}$ in particular.

Muniz, Prieto, Almeida and Bartram (1999) studied test construction and test use in Spanish- and Portuguese-speaking countries. They found the translation and adaptation of tests to be an especially relevant problem. According to them, the most common problems in the application of tests were: failure to respect the copyright of the test, use of tests inappropriate to the case, use of out of date tests, and failure to check the interpretation of tests with colleagues. The five most commonly used tests in the countries they studied, were (in order of frequency of use): Wechsler Scales, MMPI, Rorschach, Raven's and 16 PF. Except for the Rorschach and the Raven's tests, these tests were all used in the present study too.

In evaluating the findings of the present study, one has to bear in mind that this was initial, superficial, exploratory research, which involved a very small sample. Nevertheless, the findings are indicative of the typical issues that South African organisations are faced with, when implementing psychometric testing in human resource management today, and therefore cannot be disregarded.

Psychometric testing and development is at present undergoing an unstable period. It does however appear that organisations are attempting to adapt 
themselves to the instability and uncertainty, while continuing to identify and develop the human resource potential of South Africa.

Chan, Drasgow and Sawin (1999) warned that test developers and test users should pay attention to the "shelf life" of their tests - especially large-scale and well-established non-cognitive measures such as, inter alia, the $16 \mathrm{PF}$. It therefore seems a sensible suggestion that test manuals and other test material (also norms) should be updated more frequently by the distributor of a test. Consideration should also be given to the development of new tests, with special emphasis on culture-faimess - which might be enhanced by competency-based assessment, seeing that it is job-related rather than norm-based.

At present it is very important that tests be validated for the different organisations in which they are used. This also implies that in each organisation, for each specific job, the validity of the test battery used, must be ensured. Once again, this is something that might be enhanced by also making use of competency-based assessment, which is directly linked to job content and inherent job requirements. One must however bear in mind that there are psychological factors which competency measures cannot capture, such as learning or developmental potential.

This study was a qualitative investigation, and it is not always possible to obtain all the detailed information normally required by this type of research. One reason for this is that organisations often regard some psychometric information as confidential. With regard to follow-up research, an expansion of the sample is strongly required. This would also lead to a more in-depth study of the entire field of psychometric testing in human resource management.

\section{ENDNOTE}

The cooperation of everybody involved in this study, including all participating organisations, is greatly appreciated.

\section{REFERENCES}

1 AIKEN, L.R. (1994) Psychological Testing and Assessment (8th ed.) Massachusetts: Allyn \& Bacon.

2 ANASTASI, A. and URBINA, S. (1997) Psychological Testing (7th ed.) New Jersey: Prentice-Hall Inc.

3 BARTRAM, D. and COYNE, 1. (1998) The ITC/EFPPA Survey of Testing and Test Use in Countries World-Wide Narrative Report, Paper presented at workshop of International Test Commission, Dublin. 
4 CHAN, K., DRASGOW, F. and SAWIN, L.L. (1999) "What is the Shelf Life of a Test? The Effect of Time on the Psychometrics of a Cognitive Ability Test Battery", Journal of Applied Psychology, 84(4): 610-19.

5 ECKSTEIN, S. (1998) "Testing Times", People Dynamics, 17(6) 54-5.

6 EMPLOYMENT EQUITY ACT. (1998) No.55, Republic of South Africa.

7 FRIEDENBERG, L. (1995) Psychological Testing: Design, Analysis, and Use, Massachusetts: Allyn \& Bacon.

8 HUYSAMEN, G.K. (1996) Psychological Measurement. An Introduction with South African Examples, Pretoria: J.L. van Schaik.

9 KEMP, N. (1999) "Psychometric Testing is not Dead, People Dynamics, 17(3): $14-17$.

10 KRIEK, H. (1998) "Faimess and Equity: New Legislation will Help to Increase the Best Practice of Occupational Testing", Jul/Aug Newsline, SHL South Africa.

11 MEDICAL, DENTAL AND SUPPLEMENTARY HEALTH SERVICE PROFESSIONS ACT. (1974) No.56 as amended, Republic of South Africa.

12 MITTNER, M. (1998) "Psychometric Tests under Fire", F \& $T$ Weekly, 26 June, 56.

13 MUNIZ, J., PRIETO, G., ALMEIDA, L. and BARTRAM, D. (1999) "Test use in Spain, Portugal and Latin American Countries", European Journal of Psychological Assessment, 15(2): 151-7.

14 OWEN, K. and TALJAARD, J.J. (1996) Handbook for the use of psychological and scholastic tests of the HSRC, Pretoria: HSRC.

15 ROODT, G. (1998) "Challenges in Psychological Assessment", People Dynamics, 16(11): 30-4.

16 SCHULTZ, D.P. and SCHULTZ, S.E. (1998) Psychology and Work Today, (7th ed.) New Jersey: Prentice-Hall Inc.

17 SHL (1996) Assessment Materials, Saville \& Holdsworth Ltd. Occupational Psychologists.

18 SPANGENBERG, H. (1990) Assessing Managerial Competence, Cape Town: Juta.

19 THOMAS INTERNATIONAL (undated). Increasing People Effectiveness, Proceedings of a two day workshop presented by Thomas International Management Systems.

20 VAN DER MERWE, R.P. (1999) "Psychological Assessment in Industry, Journal of Industrial Psychology, 25(3): 8-11.

21 VAN DER WALT, H.S. (1998) "Psychological Tests: Refined Instruments for Reliable Information to Decision-Makers", In Focus Forum, 5(4): 16-17. 